\title{
Review of Stormwater Quality, Quantity and Treatment Methods Part 1: Stormwater Quantity Modelling
}

\author{
Rupak Aryal, J. Kandasamy, S. Vigneswaran ${ }^{\dagger}$, R. Naidu ${ }^{1}$, and S. H. Lee ${ }^{2}$ \\ Faculty of Engineering, University of Technology Sydney (UTS), P.O. Box 123, Broadway, NSW 2007, Australia \\ ${ }^{\prime}$ CRC CARE, University of South Australia, Adelaide, Australia \\ ${ }^{2}$ School of Civil and Environmental Engineering, Kumoh National Institute of Technology, Gumi 730-701, Korea
}

Received March 2009, accepted June 2009

Vol. 14, No. 2, June 2009 


\title{
Review of Stormwater Quality, Quantity and Treatment Methods Part 1: Stormwater Quantity Modelling
}

\author{
Rupak Aryal, J. Kandasamy, S. Vigneswaran ${ }^{\dagger}$, R. Naidu ${ }^{1}$, and S. H. Lee ${ }^{2}$ \\ Faculty of Engineering, University of Technology Sydney (UTS), P.O. Box 123, Broadway, NSW 2007, Australia \\ ${ }^{I}$ CRC CARE, University of South Australia, Adelaide, Australia \\ ${ }^{2}$ School of Civil and Environmental Engineering, Kumoh National Institute of Technology, Gumi 730-701, Korea
}

Received March 2009, accepted June 2009

\begin{abstract}
A review of stormwater quantity and quality in the urban environment is presented. The review is presented in three parts. The first part reviews the mathematical methods for stormwater quantity and has been undertaken by examining a number of stormwater models that are in current use. The important feature of models, their applications, and management has been discussed. Different types of stormwater management models are presented in the literatures. Generally, all the models are simplified as conceptual or empirical depending on whether the model is based on physical laws or not. In both cases if any of the variables in the model are regarded as random variables having a probability distribution, then the model is stochastic model. Otherwise the model is deterministic (based on process descriptions). The analytical techniques are presented in this paper.
\end{abstract}

Keysords: Stormwater, Quantity and quality, Mathematical models, Analytical technique

\section{Introduction}

It is estimated that by year 2025, half of the world's population will live in urban areas. As the land occupations by urban areas are very small compared to the rural areas, the human activities intensify local competition for all types of resources, with water amongst the most vital.

The development of water resources requires the conception, planning, construction and operation of facilities to control and utilize water for a variety of purposes. Stormwater infiltration is an example of use of urban excess water that will not cause excessive damage to property loss of life and inconvenience of people and the receiving aquatic bodies. ${ }^{1-4)}$

Water resource managers are faced not only to control and management of runoff water quantity but with the maintenance of water quality as well, especially during the wet weather period. ${ }^{5,6}$ Precipitation falling over an urban watershed passes through an enormously complex hydrologic and hydraulic system. As it moves through this system it concentrates into larger and larger flow streams and picks up a wide variety of pollutants in the process. An urbanized area is, by definition, an area of concen-

\footnotetext{
${ }^{\dagger}$ Corresponding author

E-mail: s.vigneswaran@uts.edu.au

Tel: +612-9514-2641, Fax: +612-9514-2633
}

trated human activity. With this activity comes an increase in runoff volumes and flow rate due to covering of much of the surface with impervious materials such as concrete, asphalt etc. ${ }^{7}$ In addition, such a concentration of human activity can only be maintained by a large influx of a great variety of materials. Some of this waste is transported from the urban area by stormwater runoff to receiving waters. ${ }^{8,9}$ This transport process is very efficient since urban areas have elaborate drainage systems to remove runoff quickly. This is made complicated in prediction by unequal distribution of water and its availability at any place varying with time. ${ }^{10)}$

Engineers have viewed urban stormwater with different perspectives over the years. In earlier times, the concern was for flood control and removing runoff as expeditiously a possible. ${ }^{11,12)}$ In more recent times, the cross purposes of removing runoff from streets and parking lots and yet not overwhelming receiving waters led to the notion of comprehensive stormwater management. ${ }^{13)}$ Everyday increasing legislation parameters enforces scientists and engineers to predict and do maintenance of water quantity and quality using different approaches. Application of computer models of urban stormwater flow and quality have been extremely useful in establishing whether various management strategies produce water quality that conforms to the legislation. However, simulation of urban runoff quality is very dif- 
ficult in getting accuracy. Previous researchers have discussed
many difficulties of simulation of urban runoff quality. ${ }^{14.17)}$ many dificulties of simulation of urban runoff quality. physical, chemical and biological process and in the acquisition of data and parameters for the model. The real mechanism of of dallatants build-up in dry weather period involves factors of pollutants build-up in dry weather period involves factors such as wind, traffic, atmospheric fall out, land surface activities ero-
sion, street cleaning and other imponderables $\left.{ }^{18,19}\right)$ Many efforts sion, street cleaning and other imponderables. ${ }^{18,19}$ Many efforts face at the begining of rainfall event and the pollutants loade during runoff by using some physically based equation ${ }^{20-23}$ The uncertainties can be dealt by collecting sufficient dat to The uncertainties can be dealt by collecting sufficient data to calibrate the model equation for qualitative simulation. Hundreds of models have been developed and practiced in stormwater anently appear in the literatures are summarized. This review illustrates the diversity of approaches and parameters that are considered in urban stormwater models. The review will try to considered in ality and quantity models and a review will try to treatment practices.

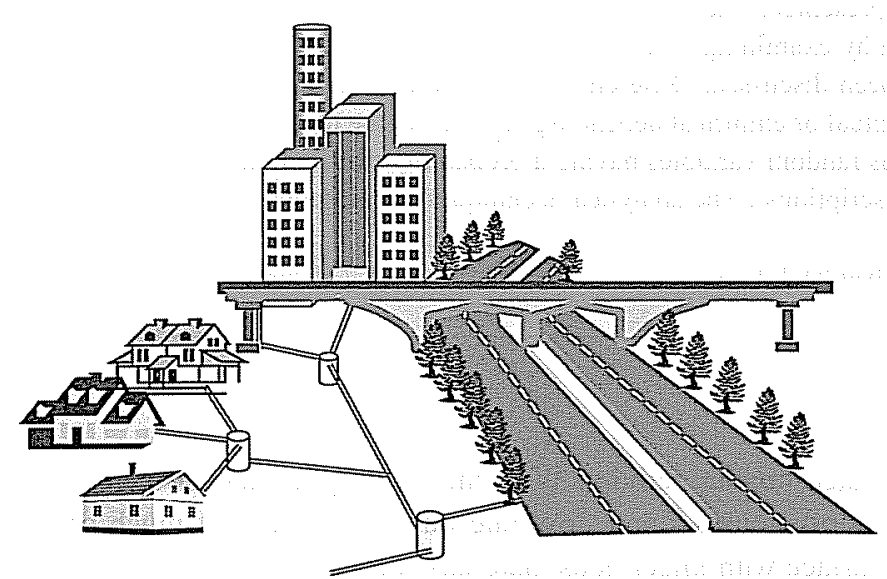

Fig. 1. Urban hydrology and drainage networking.

\section{Modelling Approaches}

Different types of stormwater management models are developed in the literatures. Generally, all the models are simplified as conceptual or empirical depending on whether the model is based on physical laws or not. In both cases if any of the varia based on physical laws or not. In both cases if any of the varia-
bles in the model are regarded as random variables having probability distribution, then the model is stochastic model. probability distribution, then the model is stochastic model.
Otherwise the model is deterministic (based on process descriptions). Commonly used stochastic techniques are regression tions). Commonly used stochastic techniques are regression,
transfer function, neural networks and system identifications. The stochastic model may produce the different response each time due to selection of random variables. In case of deterministic model, the result is always identical for the same input parameters. These models try to represent the physical processes observed in real world. Most of the urban runoff models are deterministic models. Furthermore, the deterministic models can be a single event or continuous process driven. Event mode are short term models used for simulating a few or individua storm events. Continuous models simulate a catchment's over-

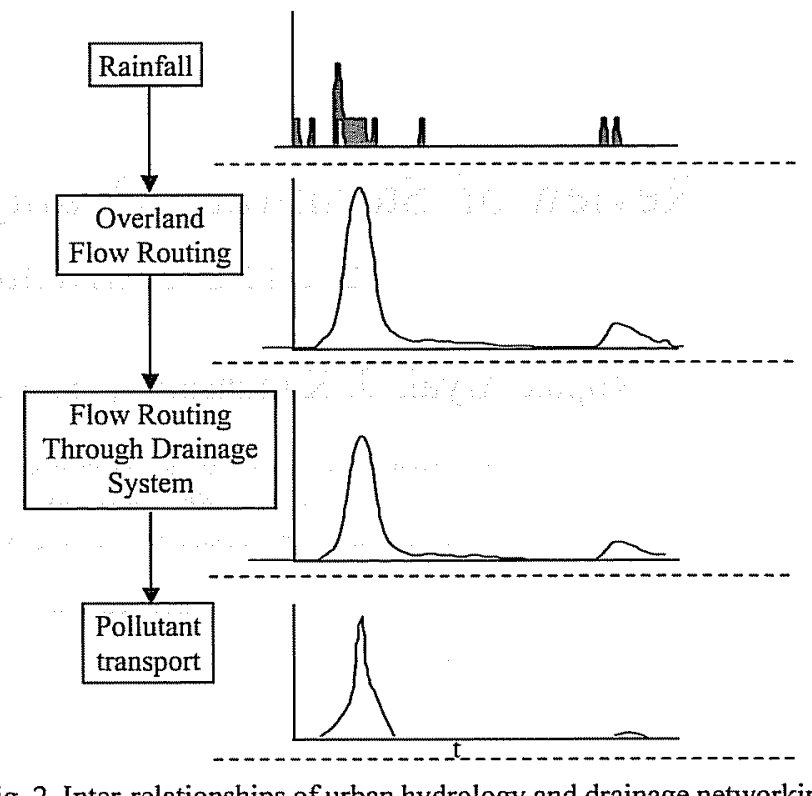

Fig. 2. Inter-relationships of urban hydrology and drainage networking

all water balance over a long period of time, involving monthly or seasonal predictions.

(i) rainfall-runoff modelling, ii) pollutants build-up and decay and ort modelling. Inter-relationships among the components are shown in Fig. 2.

\section{Urban Runoff Quantity Problems and Models}

Rain falling over an urban watershed will strike either a pervious surface or an impervious surface. On pervious surface most of the rainfall infiltrated to the subsurface and some remains runoff as overland flow and depression storage. Depression storages are small pores on land surfaces which temporarily store water. Some portion of the runoff water may be evaporated. On impervious surface nearly all the rainfall becomes .runoff due to lack of infiltration and very limited depression loss. Surface runoffs from both pervious and impervious surfaces find the way to channels streams. The runoff behaviour of stormwate varies according to the surface types. Urban drainage network channels try to overcome the runoff to much extent by accommodating the generated runoff within it. But the increased human activity and their produced conditions such as imperviousness and manmade water courses lead faster rainfall to runoff transformation resulting deleterious effects such as flooding stream erosion, habitat destruction etc.

There are three different approaches to urban stormwater modelling; namely, the design storm event approach, the continuous simulation approach, and derived probability distribution approach. ${ }^{24}$

There are several models from simple to complex. Compute aided models have been used to simulate the behaviour of aquatic systems since the mid $1960^{\prime}$ 's. Good model simulator appeared in the earlier 1970's and were developed primarily by US government agencies such as Environmental Protection Agency. Since then number of urban watershed models have been deve- loped and introduced. These models include from simple conceptual models to very complex hydraulic model.

Simple models require less data; calculations are not repetitive and may require simple calculations. The output of the calculations may provide limited information on flow and the pollutants. In case of complex models, the routing (flowing) behaviour is based on some physical laws describing the flow within the catchments. Depending on the parameters introduced they describe the behaviour of catchment in different complexities Generally there are three different approaches to urban stormwater modelling; namely, the design storm event approach, the continuous simulation approach and derived probability distribution approach. The design storm event approach is simple and does not require the historical data. The model is based on single event data. Allough it may simulate a single event and approximate rainfall runoff transformation of but it has many limitations. The nodel can not adopt the antecedent dry weather period. Moreover, if the ranfall is intermittent, the depression loss or storage loss can not be accommodated and model prediction falls. Long term performance is really critical for the model simulation. The conthus simulation approach involves conceptual modelling of he physical system, recognizing not only the properties of the storm but also the accumulative effect closely-spaced stonms. One of he major drawbacks of continuous simulation modelling is its computational burden, resulting from a large number of simulation runs to calibrate and validate a represse nive number of systom confgurations. Derived probability distibuion approach is based on the probability density function of runoff charactistics in contrast to the utilization of the probability dist

The primary benefit of the analytical models lies in the availability of explicit mathematical solutions to performance mea-

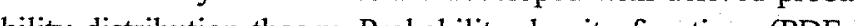
desty descing describing the system hydrology and hydralics.

4. Approaches to Stomwater Quantity Estimation

4.1. Simple Statistical and Empirical Models

Statistical models are normally developed with well established multivariate pattern recognition techniques such as factor shed multivariate pattern recognition techniques such as factor
analysis, cluster analysis, correlation analysis etc. Other frequently used techniques for developing stormwater quality models include linear, non-linear and stepwise regression equations. These models relate measured quantities such as water quantity, with measurable physical parameters that are considered im tant in a particulate process. Most of these statitical moderstochastic and applicable for single storm event These model

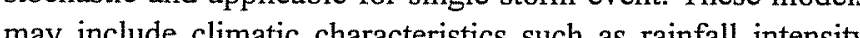
and catchment parameters (impervious area land-use type, catchment slope etc). One (tomple of liner tegresion type, given by Neter et al., $1990^{277}$ is:

\section{Similarly nonlinear regression model is}

$Y=\beta_{o} \prod_{i=1}^{n} X_{i} \beta_{i}$

In which $Y$ is dependent variable, $X_{i}$ are explanatory or observer variables and $\beta_{i}$ are the known regression coefficients, is a common statistical model used for modelling both water quality and quantity. A unit hydrograph analysis is typically applied to a single event. ${ }^{28)}$ However the time series may include severa discrete or complex wet weather events. Equation 1 may be expanded and expressed in matrix form. ${ }^{29}$

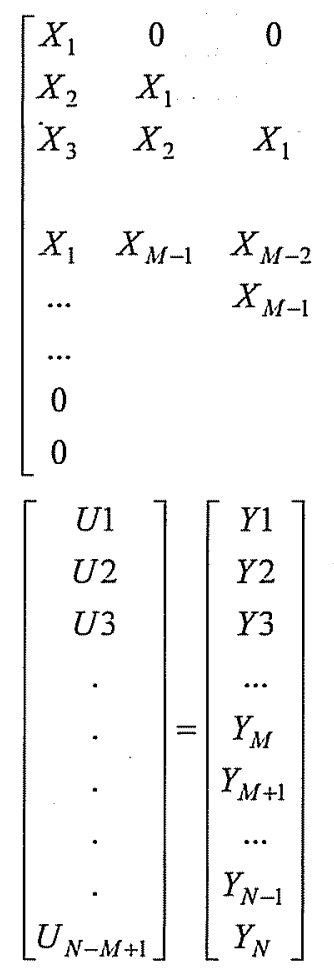

Or

$[X \llbracket U]=[Y]$

(3)

Where $X$ is the matrix of measured precipitation, in which $X_{1}$ is recorded at the end of the first time step, $X_{2}$ is recorded at the end of second time step, etc. $U$ is a vector of unit hydrograph Apparent drawback of these type

Apparent draw is they are developed from a given data set collected from a particular

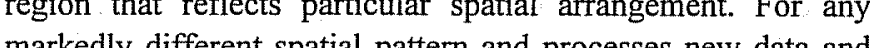
new statictic model con not consider dry wether period tale into ace

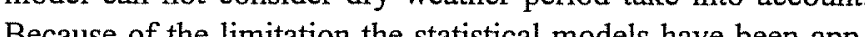
lied mainly for the crude analysis or in the sitution where lied mainly for the crade analysis or in the stuation where cient data or resorces. 
urban watershed modelling can be found in Tasker and Driver, ${ }^{23)}$ Jewell and Adria ${ }^{30}{ }^{30}$ Driver and Troutman, ${ }^{31)}$ Yao and Terakawa, ${ }^{32)}$ Khan and See.

Linder and $\mathrm{Ellis}^{34)}$ applied multiple linear-regression equation for stormwater runoff volume and peak flows in Denver, Colorado. Driver and Tasker ${ }^{33}$ applied the regression models in arid western states in USA. They emphasized regression based model in which models are calibrated to flood-frequency determination at gaged locations is the most accurate and reproducible. They developed regression models that related storm-runoff loads and volumes to easily measured physical, land-use and climatic characteristics.

Yao and Terakawa ${ }^{32)}$ applied regression model to a large Fuji river basin in Japan for meteorological parameters estimation. They applied 16 years monthly data was applied to determine the parameters and found the model good agreement with the observed data which they applied in distributed model for the runoff estimation.

\subsection{Dynamic Wave Equation}

The flood flow is unsteady- as the flow properties (depth and velocity) changes with time, is gradually varied, because such change with time is gradual. The basic llow-governing equations are the dynamic wave equations, often referred to as the St.

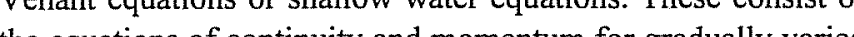
the equations of continity and moment

$$
\frac{\partial h}{\partial t}+\frac{\partial Q}{\partial x}=0 \quad \text { (continuity) }
$$

(4) $\quad Q=\frac{1}{n} A R^{2 / 3} S_{f}^{1 / 2}$

$\frac{\partial u}{\partial t}+u \frac{\partial u}{\partial x}+g \frac{\partial h}{\partial x}=g\left(S_{o}-S_{f}\right)$ (momentum)

(5) where,

$n$ is Manning's roughness coefficient, $A$ is flow cross-sectional area per unit width $\left(\mathrm{m}^{2} / \mathrm{m}\right), R$ is hydraulic radius.

4.4. Kinematic Wave Equation

As we stated above the dynamic wave equation has numerical solutions. Depending on the accuracy desired, alternative flood soluting. Dutions are generated by using the complete food routing equato while eliminating some terms of the momentinuly equation. These dynamic wave equations have not been used in watershed modes becuse of their computationally intensive equations on a limited basis.

The first application of kinematic wave theory to pollutan transport was made by Brazil et al. ${ }^{40}$. They applied the theory to simulate non-point pollutant in overland flow. Later on Snyder and Woolhisert) ${ }^{41}$ elaborated the equation by including the infiltration effect. $\mathrm{Akan}^{42}$ ) developed a kinematic wave model for pollutant wash-off by the overland flow on impervious surfaces. Havis et at ${ }^{43}$ partitioned solute transport between infilfaces. Havis etal. partis under rainfll. Singh et al ${ }^{4+4}$ proposed the diment kin transport where he primally asumed the pollutant tanspot by the runoff in urban district in China stormwater is fully mixed in the runoff water either instantaneously or in a finite period of time. The equations were further elaborated and several solutions were made by Singh, ${ }^{45}$ Deng et al ${ }^{46}$ and Guo. ${ }^{47)}$

In Kinematic wave, the friction force term $g\left(S_{o}-S_{f}\right)=0$, or $S_{o}$

$\frac{\partial h}{\partial t}+\alpha n h^{n-1} \frac{\partial h}{\partial x}=q$

with

$Q=u h=\alpha h^{n}, u=\alpha h^{n-1} c=\alpha n h^{n-1}=n$

where $h$ is the depth of the flow (L), $C$ is wave celerity, $q$ is the constant rate of rainfall excess, $Q$ is discharge per unit width $\left(\mathrm{L}^{2} / \mathrm{T}\right), q$ is rainfall intensity $(\mathrm{L} / \mathrm{T}), t$ is time $(\mathrm{T}), x$ is space coordinate (L) positive in the direction of flow, $n$ is exponent, and ais a depth-discharge coefficint or knematic wave resistant parameter. For example if Darcy-Weisbach formula is

$\alpha=\frac{8 g S_{0}}{C v}$

Where $\mathrm{C}$ is the laminar flow resistance factor and $\mathrm{v}$ is kinematic viscosity of water and $\mathrm{m}=3$.

If the Manning equation is employed then

$\alpha=\left(\frac{k}{n}\right) S_{o}^{1 / 2}$ and $\mathrm{m}=5 / 3$

A very important kinematic flow parameter is the time at which the overland flow reaches the equilibrium under constan rate of rainfall excess. The time to equilibrium can be determined using;

$$
t_{e}=\frac{L^{1 / m}}{\left(\alpha i_{o}^{m-1}\right)^{1 / m}}
$$

Where,

$t_{e}$ is time to equilibrium, $\mathrm{L}$ is the length of overland plane, $i_{o}$ is constant rate of rainfall excess

Many watershed models such as DWSM, KINEROS, and PRMS are based on the kinematic wave equations. KINEROS and PRMS use approximate numerical solutions while DWSM uses analytical and an approximate shock-fitting (closed form) solution.

4.5. Hydrological Linear Reservoir Model

Hydrological model ignores the spatial variability in the proem. They are generally based on the conservation of mass only. The unit hydrograph, lumped continuity or storage models, the Muskingum method and nonlinear storage are considered here to be hydrological methods. Some hydrological models can be interpreted as hydraulic model. The Murkingum mod is one approach that can be described as an approxinto to the shatlow water wave equations or in an af the connerto the shalThere are two types of model: liner and onlines In line Thantan (unit hydrograph) it is as aumed tht the catchent (1)

$S=K O$

In which $S$ is the storage, $O$ is the outflow and $K>1$ is constant storage coefficient. Combined with the continuity equation for the reservoir.

$\frac{d s}{d t}=I-O$

where,

$I$ is the inflow, the exponential form of the instantaneous unit hydrograph for a single storage is

$O(t)=\frac{1}{K} \exp (-t / K)$

A large catchment can be subdivided into equal subcatchments with each subcatchment considered as a separate linear storage. The instantaneous unit hydrograph for a cascade of non linear reservoir is given by ${ }^{49)}$

$O(t)=\frac{1}{K(n-1) !}\left(\frac{t}{K}\right)^{n-1} \exp (-t / K)$

which resembles a Gamma function. This model is linea because $\mathrm{K}$ is constant and does not consider translation of the flow.

In case of continuous or storage model, it satisfies the conservation of mass. The catchment response is instantaneous because the momentum equation is completely ignored. Replacing the spatial derivatives in Equation $\partial A / \partial t=\partial Q / \partial x=q$ with finite differences si that $\partial Q / \partial x=(I-O) / \Delta x$ the

$\frac{d S}{d t}=I-O$

In which is the storage $S=A \Delta x$. This equation is known as the storage equation which is used in simple routing methods.

4.6. Storage-based or Non-linear Reservoir Equations (continuous)

Nonlinear models, the storage is expressed as a nonlinear function of outflow so that

$S=K O_{w}^{m}$

ter


where $m$ is some power. Substituting into the discretised storage.

$$
O_{w}=X I+(1-X) O
$$

and models which include translation ${ }^{50)}$ have been developed. Many of the models such as ANSWERS, ANSWERS-Continuous, HSPF, INFOWORKS use the simple storage-based equations for flow routing. The equation consists of the spatially uniform and temporarily variable continuity equation and a flow equation expressed in terms of channel (or plane) roughness and geometry, such as Manning's equation, as expressed below:

$$
\frac{d s}{d t}=I-O
$$

$Q=\frac{1}{n} A R^{2 / 3} S_{0}^{1 / 2}$

where,

$s$ is the storage volume of water $\left(\mathrm{m}^{3}\right), I$ is the inflow rate $\left(\mathrm{m}^{3} / \mathrm{s}\right)$ and $O$ is the outflow rate $\left(\mathrm{m}^{3} / \mathrm{s}\right)$

\subsection{Curve Number and Empirical Equation}

Soil Conservation Service developed Curve Number (CN) as an index combining hydrologic soil group and land use factors (cover and condition). SCS curve numbers are used to estimate the amount of precipitation which becomes runoff, and the amount which infiltrates into the soil.

The curve numbers are selected from tabulated values for fallow or appropriate land use, treatment, and hydrologic conditions (crop condition) plus an antecedent moisture adjustment. Runoff and infiltration volumes can be calibrated by entering override curve numbers for a field. The standard SCS-CN method. ${ }^{51)}$ The SCS Curve Number model is mainly applied for the agricultural condition.

Many of the models, such as SWAT, AGNPS and AnnAGNPS, do not route water using mass conservation based continuity equations as described above. SWAT and AnnAGNPS maintain water balance through accounting daily or subdaily water budgets. All three of them use the USDA Soil Conservation Service runoff curve number method to compute runoff volumes and ther empirical relations similar to the Rational formula ${ }^{33)}$ to compute peak flows, which may be expressed as:

$$
Q_{r}=\frac{\left(P-0.2 S_{r}\right)^{2}}{P+0.8 S_{r}}
$$

$S_{r}=\frac{254000}{C N}-254$
$Q_{r}$ is direct runoff (mm), $P$ is accumulated rainfall $(\mathrm{mm}), S_{r}$ is potential difference between rainfall and direct runoff $(\mathrm{mm})$, $C N$ is curve number representing runoff potential for a soil cover complex (values 2 to 100$), O_{\mathrm{p}}$ is peak runoff rate $\left(\mathrm{m}^{3} / \mathrm{s}\right.$ ) $C$ is the runoff coefficient (values 0.02 to 0.95$), i$ is rainfall $C$ is

Jacobs et al ${ }^{\text {54) }}$ used SCS Curve Number to improve rainfall Junferim soil moisture. Tkenberry et al ${ }^{55}$ ) worked on $\mathrm{CN}$ number and concluded that good elevation data set is important for effective measurement of runoff depth, runoff volume and peak discharge. Barros et a $1^{56}$ applied the SCS Curve Number method to predict the peak flood runoff for Sao Paolo.

4.8. Analytical Probabilistic Models

This model provides an alternative approach to the analysis of urban drainage. The primary benefit of the model lies in the availability of explicit mathematical solutions to performance measures. A range of system design element or required performance levels can be investigated with ease wile incorporating the full range of meteorological conditions. Early work in the model was done by Howard ${ }^{57}$ then elaborated by Adams and Bontje ${ }^{58)}$ the analytical models using derived probability distribution theory. Chen and Adams ${ }^{24)}$ recently explained more about the model. To develop the expression for runoff quantity control, the input precipitation (v) is transformed into runoff (vr) using the following relationship:

$v_{r}= \begin{cases}0 & ; v \leq S_{d} \\ \Phi\left(v-S_{d}\right) & ; v>S_{d}\end{cases}$

where,

$v_{r}$ is the runoff volume (mm), $v$ is the rainfall volume, $S_{d}$ is the depression storage on the catchment expressed as an equivalent uniform depth across the entire catchment (mm), and $\Phi$ is the runoff coefficient.

A catchment reacts to rainfall by first filling the depression storage volume, $S_{d,}$, prior to runoff generation. The rainfall volume exceeding depression storage $\left(v-S_{d}\right)$, is multiplied by the runoff coefficient, $\Phi$, to determine the runoff volume $v_{r}$ The total losses, $S_{d}$ and $(1-\Phi)\left(v-S_{d}\right)$ can be viewed as a combination of infiltration and some evaporation. In analytical model, the number of average annual runoff events, $\left(n_{R} / y r\right)$, outlines the number of rainfall events which actually generate surface runoff to be routed through a stormwater drainage system and is described by

$n_{R}=\theta e^{-\xi_{d}}$

Where,

$\theta$ is the average annual number of rainfall events and $\zeta$ is the inverse of the mean rainfall event volume $(1 / \mathrm{mm})$
The average annual surface runoff volume washing off the catchment, $R(\mathrm{~mm} / \mathrm{yr})$ is described by:

$R=\theta \frac{\Phi}{\zeta} e^{-\zeta S_{d}}$

And the probability per event of a spill of any magnitude is given by

$G_{P}(0)=\left[\frac{\lambda / \Omega}{\lambda / \Omega+\zeta / \Phi}\right]\left[\frac{\psi / \Omega+\zeta / \Phi e^{-(\psi / \Omega+\zeta / \Phi)}}{\psi / \Omega+\zeta / \Phi}\right] e^{-\zeta S_{d}}$

where,

$\lambda$ is the inverse of the mean rainfall event duration (1/hr), $\Psi$ is inverse of the mean inter-event time ( $1 / \mathrm{hr}$ ), $\Omega$ is the controlled release rate from storage ( $\mathrm{mm} / \mathrm{hr})$, $S_{d}$ is the active storage volume averaged over catchment area $(\mathrm{mm})$ and $G_{p}(0)$ is probability per rainfall event of any spill of any magnitude.

\section{Conclusion}

This paper reviews mathematical methods used in stomwater modelling and has been undertaken by examining a number of models that are in current use. Generally, all the models are simplified as conceptual or empirical depending on whether the model is based on physical laws or not. In both cases if any of the variables in the model are regarded as random variables having a probability distribution, then the model is a stochastic model. Otherwise the model is deterministic (based on process descriptions). The analytical techniques are presented in this paper.

\section{Acknowledgement}

The research is funded by CRC for Contaminant Assessment and Remediation of the Environment (CRC CARE) Australia through the Grant Number 2.5.07-07/08.

\section{References}

1. Boxall, A. B. A. and Maltby, L., "The effects of motorway runoff on freshwater ecosystems: 3 . Toxicant confirmation Arch. Environ. Contam. Toxicol., 33, 9-16 (1997).

2. Brent, R. N. and Herricks E. E., "Post-exposure effects of brief cadmium, zinc, and phenol exposure on freshwate

organisms," Environ. Toxicol. Chem., 17, 2091-2099 (1998). centrations and organic trace pollutants in roof runoff, Water Sci. Technol., 38(10), 83-90 (1998).

4. Gichner, T., Patkova, Z., Szakova J., and Demnerovaare, K. "Toxicity and DNA damage in tobacco and potato plants growing on soil polluted.with heavy metals," Ecotoxico. Environ. Saf., 65(3), 420-426 (2006).

5. Hoffman, E. J., Mills, G. L., Latimer, J. S., and Quinn, J. G, "Urban runoff as source of polycyclic aromatic hydroca bons to coastal waters," Environ. Sci. Technol, 18(8), 580587 (1984).

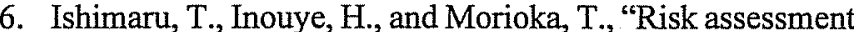
of drinking water in a reservoir contaminated by PAHs oriinged from road traffic" Sci Total Environ. (1990).

7. Chebbo, G., Gromaire M. C., Ahyerre, M, and Garnaud, S, "Production and transport of urban wet weather pollution in "Combined sewer systems: the "Maris" experimental urban catchment in Paris," Urban Water, 3, 3-15 (2001).

8. Estebe, A., Boudries, H., Mouchel, J-M and Thevenot, D. $R$, Urban runoff impacts on particulate metal and hydrocarbon concentrations in river Seine: suspended solid and ediment transport, Water Sci. Technol., 36(8-9), 185-193 (1997).

9. Sriyaraj, K. and Shutes, R. B. E., "An assessment of the impact of motorway runoff on a pond wetland and stream, Environ. International, 26, 433-439 (2001).

10. Pitt, R., Small storm urban flow and particulate wash off contribution to outfall discharge UMI Ann Arbor MI pp. 285-292 (1987).

11. Fujita, S., "Experimental sewer system for reduction of urban storm runoff", Proc. of $3 r d$ International Conference on Urban Drainage, Gutenberg, Sweden (1984).

12. Ferguson, B. K..."Storm-water infiltration for peak-flow control," J. Irrigation and Drainage Engineering, 121(6), 463-466 (1995).

13. Pitt, R., Field, R., Lalor, M., and Brown, M., "Urban stormwater toxic pollutants: assessment, sources and treatability," Water Environ. Res., 67(3), 260-275 (1995).

14. Bartosova, A. and Novotny, V., "Model of spring runoff quantity and quality for urban watersheds," Water Sci. Technol. 39(12), 249-256 (1999).

15. Grum, M., "Incorporating concepts from physical theory into stochastic modelling of urban runoff pollution," Water Sci. Technol., 37(1), 179-185 (1998).

16. Li, J. Y. and Adams, B. J., Probablistic models for analysis of urban runoff control systems, J. Environ. Eng 126(3) $217-224(2000)$.

17. Tomanovic, A. and Maksimovic, C., "Improved modelling of suspended solids discharge form asphalt surface during storm event," Water Sci. Technol., 33(4-5), 363-369 (1996).

18. Sharma M. and McBean, E., "Atmospheric PAH deposition: Deposition velocities and washout ratios," J. Environ Eng., 128(2), 186-195 (2002).

19. Vardar, N., Mustafa, O., and Holsen, T. M., "Particulate dry deposition and overall deposition of polycyclic aromatic hydrocarbons," J. Environ. Eng., 128(3), 269-274 (2002).

20. Egodawatta, P., Thomas, E., and Goonetilleke, A.. "Mathmatical interpretation of pollutant wash-off from urban road surfaces using simulated rainfall," Water Res, 41, 3025-3031 (2007).

21. Legret, M. and Pagotto, C., "Evaluation of pollutant loading in the runoff waters from a major rural highway," Sci. Total Environ., 235, 143-150 (1999).

22. Sartor, J. and Boyd, G., Water pollution aspects of street surface contaminants, EPA-R2-72-081, US EPA (1972).

23. Tasker. G. D and Driver, N. E "Nationwide regression 
models for predicting urban runoff water quality at unmonitored sites," Water Resour. Bulletin, 24(5), 1091-1101 (1988).

24. Chen, J. and Adams, B. J., "Development of analytical models for estimation of urban stormwater runoff," J. Hydrol., 336, 458-469 (2007).

25. Aryal, R. K., Dynamic behaviour of suspended solids and particle associated micropollutants in a highway runoff, PHD Thesis, University of Tokyo, Japan (2003).

26. Aryal, R. K, Furumai, H., Nakajima, F., and Hossain, M. A., "Vertical distribution and speciation of heavy metals in stormwater infiltration facilities: possible heavy metals release to groundwater," Water Practice and Technology, 2(2), (2007).

27. Neter, J., Wasserman, W., and Kutner, M. H., Applied linear statistical models, regression, analysis of variance and experimental design, 3rd ed., Irwin, Homewood, IL (1990).

28. Dodge, J. and Bruen, M., "Unit hydrograph stability and linear algebra," J. Hydrol., 111, 377-390 (1989).

29. Mays, L. W. and Coles, L., "Optimization of unit hydrograph determination," Journal of Hydraulics Division, 106, HY1, 85-97 (1980).

30. Jewell, T. K. and Adrian, D. D., "Development of improved stormwater quality models," Journal of the Environmental Engineering Division, Proc. ASCE, 107(EE5), 957-974 (1981).

31. Driver, N. E. and Troutman, B. M., "Regression models for estimating urban storm-runoff quality and quantity in the United States, $J$. hydrol, , 109(3-4), 221-236 (1989).

32. Yao, H. and Terakawa, A., "Distributed hydrological model for Fuji River basin," J. Hydrol. Eng., 4(2), 108-116 (1999).

33. Khan, S. A. and See, L., "Rainfall-runoff modelling using data driven and statistical methods," Proc. RAST, Space Technologies for Disaster Management and Rehabilitation, 16-20, Pakistan (2006).

34. Linder-Lundsford, J. B. and Ellis, S. R., "Comparison of Conceptually Based and Regression Rainfall-Runoff Models, Denver Metropolitan Area, Colorado, and Potential Applications in Urban Areas," U.S. Geological Survey WaterResources Investigation Report 87-4104, Denver, Colorado, pp.39 (1987).

35. Driver, N. E., and Tasker, G. D., Techniques for estimation of storm-runoff loads, volumes and selected constituent concentration in urban watersheds in the United States, US, Geological Survey, Open File Report 88-91 (1988).

36. Barkau, R. L., UNET: One-Dimensional Unsteady Flow Through a Full Network of Open Channels: Users Manual, US Army Corp of Engineers, Hydrologic Engineering Center, Davis, CA (1993).

37. Aronica, G. T. and Lanza, L. G., "Drainage efficiency in urban areas: A case study," Hydrological Processes, 19(5), 1105- 1119 (2005).

38. Liu, J. X. and Shao, W. Y., "Simulation of rainfall runoff in urban district (in Chinese)," Shuili Xuebao/J. Hydraulic Eng., 37(2), 184-188 (2006).

39. Singh, V. P., Kinematic Wwave Modelling in Water Resources: Surface-Water Hydrology, John Wiley and Sons, NY (1996).

40. Brazil, L. E., Sanders, T. G., and Woolhsier, D. A., Kine- matic parameter estimation for transport of pollutant in overland flow, In: Surface and Subsurface Hydrology, Morel Seytoux HJ (ed), Water Resources Publications, Fort Colloins, CO, pp. 555-568 (1979).

41. Snyder, I. K. and Woolhiser, D. A., "Effect of infiltration on chemical transport into overland flow," $A S A E, 28,1450$ 1457 (1985).

42. Akan, A. O., "Pollutant washoff by overland flow," $J$. Environ. Eng., 113(4), 811-823 (1987).

43. Havis, R. N., Smit, R. E., and Adrian, D. D., "Partitioning solute transport between infiltration and overland flow under rainfall," Water Resour. Res., 28(10), 2569-2580 (1992).

44. Singh, V. P., Kinematic Wave Modeling in Water Resources: Environmental Hydrology, Wiley, NY (1997).

45. Singh, V.P., "Kinematic wave solution for pollutants transport by runoff over an impervious plane, with instantaneous or finite-period mixing," Hydrol. Process, 16, 1831-1836 (2002).

46. Deng, Z. Q., de Lima, J. L. M., and Sing, V., "Fractional kinetic model for first flush of stormwater pollutants," $J$. Environ. Eng., 232-241 (2005).

47. Guo, J. C. Y., "Storm-water prediction by dimensionless unit hydrograph," J. Irrigation and Drainage Eng., 132(4), 410417 (2006).

48. Chow, V.T., Handbook of Applied Hydrology: A Compendium of Water Resource Technology : Section 14, McGrawHill, NY (1964).

49. Nash, J. E., "The form of the instantaneous unit hydrograph," IASH Publicatio, 45(3,4), 114-121 (1957).

50. Dodge, J. C. I. and Bruen, M., "Unit Hydrograph Stability and Linear algebra," J. Hydrol., 111, 377-390 (1989).

51. USDA-SCS, National Engineering Handbook: Section 4Hydrology (revised), Washington, D. C. (1985).

52. USDA-SCS, National Engineering Handbook: Part 630 Hydrology Section 4, US Government Printing Office, Washington, D. C. (1972).

53. Kuichling, E., "The relation between rainfall and discharge of sewer in populous district," ASCE, 20(402), 1-60 (1889).

54. Jacobs, J. M., Myers, D. A., and Whitfield, B. M., Improved rainfall/runoff estimates using remotely sensed soil moinsture, J. American Water Resource Association, 39(2), 313324 (2003).

55. Ikenberry, C., Darkwah, S., Walton, J., and McCole, P., "Using GIS to assess effects of spatial data resolution on watershed hydrology," Watershed 2004 Conference Proceeding, Water Environment Federation, CD-ROM (2004).

56. Barros, M. T. L., Porto, M. F. A., and Brandao, J. L. B., "Urban catchment management," Pro. Watershed Management Conference-Managing Watershed for Human and Natural Impacts: Engineering, Ecological and Economic Challenges, ASCE, 1657-1668 (2005).

57. Howard, C. D. D., "Theory of storage and treatment plant overflows," J. Environ. Eng., ASCE, 102(EEA), 709-722 (1976).

58. Adams, B. J. and Bontje, J. B., Microcomputer applications of analytical model for urban stormwater management. In: James, W. (Ed.), Emerging Computer Techniques in Stormwater and Flood Management, ASCE, NY, 138-162 (1984). 